\title{
Molecular mechanisms in septic shock (Review)
}

\author{
GABRIEL GORECKI $^{1}$, DANIEL COCHIOR ${ }^{2-4}$, COSMIN MOLDOVAN $^{2,5}$ and ELENA RUSU ${ }^{2}$ \\ ${ }^{1}$ Medicine Doctoral School, 'Titu Maiorescu' University of Bucharest, 040317 Bucharest; \\ ${ }^{2}$ Faculty of Medicine, 'Titu Maiorescu' University of Bucharest, 031593 Bucharest; \\ ${ }^{3}$ General Surgery, 'Monza' Clinical Hospital, 021967 Bucharest; \\ ${ }^{4}$ General Surgery, 'Sanador' Clinical Hospital, 010991 Bucharest; \\ ${ }^{5}$ General Surgery Ward, 'Witting' Clinical Hospital, 010243 Bucharest, Romania
}

Received May 11, 2021; Accepted June 10, 2021

DOI: $10.3892 /$ etm.2021.10595

\begin{abstract}
Sepsis is a clinical syndrome defined by the presence of infection and systemic inflammatory response to infection and results from a complex interaction between the host and infectious agents. It is characterized by the activation of multiple inflammatory pathways, with an increased risk of mortality. The incidence of sepsis has been on an ever-increasing pathway in recent years. Sepsis can be induced by several clinical situations that predispose to its occurrence: malignant tumors, organ transplantation, AIDS, radiation therapy, burns, sores, polytrauma, diabetes mellitus, hepatic failure, renal failure, malnutrition, catheters or different invasive devices, and urinary catheters. The microorganisms involved in the pathogenesis of sepsis are Gram-positive cocci (Staphylococci, Streptococci) and Gram-negative bacilli (Klebsiella, Pseudomonas aeruginosa, E. coli), fungi (Candida), parasites, and viruses. Among mechanisms involved in septic shock production, two pathological phenomena appear: the profound decompensation of circulation and metabolic disturbances that evolve towards an irreversible state. The intimate mechanism of shock involves the activation of monocytes, macrophages and neutrophils by lipopolysaccharides of Gram-negative bacteria. The microvascular bed is directly involved in the etiopathogenesis of disorders of acute inflammatory states associated with or without sepsis. A better comprehension of sepsis pathophysiology, especially the molecular mechanisms of septic shock, allows for new therapeutic perspectives.
\end{abstract}

\section{Contents}

1. Introduction

2. Mechanisms in septic shock

Correspondence to: Dr Cosmin Moldovan, Faculty of Medicine, 'Titu Maiorescu' University of Bucharest, 67A Gheorghe Pătraşcu Street, 031593 Bucharest, Romania

E-mail: cosmin.moldovan@prof.utm.ro

Key words: molecular mechanisms, septic shock
3. The septic syndrome

4. Infection and dissemination in septic shock

5. Conclusions

\section{Introduction}

Sepsis is a systemic inflammatory response developed by an organism following an infection. It is manifested by two or more associated states as a result of infection $(1,2)$. These associated states are infection, bacteremia as well as a systemic inflammatory response to a variety of severe clinical situations [systemic inflammatory response syndrome (SIRS)]. SIRS is manifested by at least 2 of the following clinical signs: temperature $\left(>38^{\circ} \mathrm{C}\right.$ or $<36^{\circ} \mathrm{C}$, heart rate $>90 / \mathrm{min}$, respiratory rate $>20 / \mathrm{min}$ or $\mathrm{PaCO}_{2}<32 \mathrm{mmHg}$ and a leukocyte count of at least 12,000 cells $/ \mathrm{mm}^{3}$ or $<4,000$ cells $/ \mathrm{mm}^{3}$ or $10 \%$ immature cells (3).

Weil and Shubin (4) classified shock into 4 distinct types: Hypovolemic (loss of intravascular volume), cardiogenic, obstructive (heart, arteries and large veins) and distributive. The state of septic shock is represented by the presence of sepsis associated with hypotension although the resuscitation of adequate depletion occurs.

Sepsis can be induced by several clinical situations that predispose to its occurrence: malignant tumors, organ transplantation, AIDS, radiation therapy, burns, sores, polytrauma, diabetes mellitus, hepatic failure, renal failure, malnutrition, catheters or different invasive devices, urinary catheters, and others (5-9). The most common bacterial species that can induce sepsis are Gram-negative bacteria (E. coli, Klebsiella, Pseudomonas aeruginosa) as well as other micro-organisms such as mycobacteria, fungus (Candida, Histoplasma, Aspergillus), different types of viruses and protozoa (10). Gram-negative bacteria induce mainly urosepsis while Gram-positive bacteria are responsible for inducing sepsis in about $15 \%$ of cases (11). These microbial species have as entry points the genitourinary-urinary tract, gastrointestinal or respiratory tract, various wounds, and others $(12,13)$. In patients with septic shock, the oxygen needs are greatly increased in a situation when its intake and transport to tissues is altered, partly due to the closure of the microvascular shunts (14). The monitoring of patients with septic states may be difficult due to 
discrepancies between central (macro-hemodynamic) circulation and microcirculation in internal organs (splanchnic) (15).

\section{Mechanisms in septic shock}

Sepsis is the systemic response of the body to a severe infection causing a complex of interactions between the host and the pathogenic organism resulting in the response of inflammatory mediators (16). The shock is characterized by a decrease in oxygenated blood tissue flow below the critical level necessary for normal conduct of cellular metabolic processes (17). Septic shock represents hypoxic tissue distress associated with the presence in the blood of pathogenic germs (18).

The incidence of sepsis has been on an ever-increasing pathway in recent years, as a result of longer life expectancy of the population as well as the association of comorbidities, such as cancer, immunosuppression, diabetes mellitus and chronic organ dysfunction (19). The mortality rate in intensive care units (ICUs) is generally $37 \%$ and in hospital wards it is approximately $45 \%$ (20). It is well known that septic states, and specifically septic shock, associated with various pathologies, significantly increase the mortality rate of these patients. The incidence of septic states is approximately 3 out of 1,000 inhabitants, with a high mortality, ranging from 28 to $80 \%$, depending on the severity of the sepsis, the number of dysfunctions/insufficiencies of organs occurring during clinical evolution, age and pre-existing morbidities (21). Immediate death, within 3 days of admission to the ICU, generally occurs in about $32 \%$ of cases, later deaths (about a few days or weeks) occur in around $68 \%$ of cases (22-24). Determinants of immediate death include age, malignancy, diabetes mellitus as well as the initial level of severity, but cancer is also a factor with an increased rate of importance (25). For patients that survive for more than 3 days, the factors involved in delayed death include: age, cirrhosis and treatment with previous corticosteroids (21). Moreover, various associations of comorbidities, such as anemia developed in inflammatory bowel disease, may increase significantly the mortality rate (26). Infection with Gram-negative, Gram-positive, rickettsia or viruses produces a septic status characterized by a temperature above $38^{\circ} \mathrm{C}$ or below $36^{\circ} \mathrm{C}$, tachycardia, tachypnea (over 20 breaths/min), leukocytosis over 12,000 or below 4,000 cells $/ \mathrm{mm}^{3}$, or the presence of neutrophils in excess of $10 \%$ (13).

In septic shock, tissue hypoxia plays a role in reduced oxygen intake and delivery to tissues through the deficient distribution of peripheral blood flow under the action of microbial endotoxins and the increased concentration of mediators released (27). The most studied mechanism is the inflammatory response triggered by the endotoxin released by Gram-negative germs. This is a polysaccharide and has the following three effects: i) Increased permeability with extravasation fluid in interstitial space on endothelial cells results, with the activation of platelets and the coagulation; ii) activation of the XIIth factor (Hageman) which initiates the process of coagulation, and of fibrinolysis; iii) activation of complement, with the release of $\mathrm{C}_{3 \mathrm{a}}, \mathrm{C}_{4 \mathrm{a}}$ and $\mathrm{C}_{5 \mathrm{a}}$ components that stimulate neutrophil aggregation and their fixation on capillary endothelium.

At the pulmonary level, various lesions that could lead to continuous life-long treatment may develop (28). The endotoxin's capacity to induce the release of various cytokines also occurs inside the lungs by producing these mediators by alveolar macrophages (29). The microvascular bed is directly involved in the etiopathogenesis of disorders of acute inflammatory states associated with or without sepsis (systemic inflammatory response syndrome, anti-inflammatory compensatory syndrome) with direct visceral response (multiple organ dysfunction). According to some authors, these mechanisms also appear to be exacerbated by the presence of malignant tumors, such as adenocarcinoma (30-33).

\section{The septic syndrome}

Systemic inflammatory response syndrome (SIRS) is clinically recognized by a series of objective clinical signs, cardinal, that include tachypnea, fever or hypothermia, tachycardia and leukocytosis or leukopenia with left deviation of the leukocyte formula. SIRS may be the result of infectious or non-infectious causes (19). Non-infectious causes associated with SIRS include trauma, burns, hemorrhagic or hypovolemic shock and, as a major cause, pancreatitis (34).

Sepsis is defined as an SIRS resulting from infections, regardless of the determining agent-bacterial or viral. Its severity is directly proportionate to the intensity of the host body's response. Severe sepsis is defined as sepsis associated with multiple organ dysfunctions (35). Septic shock occurs when systemic hypotension is associated with tissue hypoperfusion and anaerobic metabolism. This simple classification aims to deliver the prognosis of mortality in SIRS (7\%), sepsis $(16 \%)$, severe sepsis $(20 \%)$ and septic shock (>46\%). Grading the septic syndrome reflects the increase in the systemic inflammatory response correlated with worsening of the clinical signs (36). Multiple organic dysfunction syndrome (MODS) is defined by the presence of functional deterioration of at least 2 organs, as an indicator of the impossibility of maintaining homeostasis. In most cases the following organ systems are affected (in order of increased severity): the cardiovascular system (tissue hypoperfusion), pulmonary system (acute pulmonary or ARDS), renal system (acute renal failure), blood (intravascular disseminate coagulation, thrombopenia), nervous system (encephalopathy), vascular endothelium (generalized edema), and the liver (unspecified hepatitis, acute hepatic failure) (37,38).

Microbial species or their endotoxins meet sterile tissues and activate the immune defense mechanisms of host cells. Macrophages engulf bacteria or endotoxins and release several primary mediators. These primary mediators are known to be cytokines, which in turn initiate a cascade of inflammatory reactions. The following inflammatory systems have been shown to be activated in this respect. i) Phospholipase $\mathrm{A}_{2}$ releases phospholipids that are metabolized through the enzyme system of the cyclooxygenases and lipooxigenesis in prostaglandins and leukotrienes (39). These substances determine fever (especially prostaglandin $\mathrm{PGE}_{1}$ with effect the hypothalamus), vasodilation with increased cellular permeability (40). ii) The Hageman factor determines the initiation of the coagulation cascade and the activation of the quinine system. iii) The complement system is in turn activated; the result is the production of $\mathrm{C}_{3 \mathrm{a}}$ and $\mathrm{C}_{5 \mathrm{a}}$ (with a destructive bacterial effect), increased vascular 
permeability which acts as permeability factor agents for leukocytes (41).

Prostaglandins are synthesized by most cells of the human body. The enzymes involved in the metabolism of arachidonic acid regulate the cellular level of arachidonic acid that remains in an esterification form until its transformation by phospholipase (especially by phospholipase PLA $\mathrm{A}_{2}$ ) occurs $(42,43)$. In the endoplasmic and the nuclear membranes, the arachidonic acid obtained under $\mathrm{PLA}_{2}$ action, is subjected to the action of prostaglandin synthase $\mathrm{H}$ (PGHS) and then it is metabolized to prostaglandin $\mathrm{H}_{2}\left(\mathrm{PGH}_{2}\right)$. PGHS exists in two forms of isomers: PGHS-1, known as COX-1 (cyclooxygenase) and PGHS-2, known as COX-2. Isoenzyme COX-1 is responsible for $\mathrm{PG}$ biosynthesis, in a general mode, while COX-2 is involved in the anti-inflammatory processes (44).

Prostaglandins activate specific receptors that can be cellular-specific or tissue-specific. At least 9 classes of PG receptors are known. Exceptionally, the $\mathrm{EP}_{3}$ receptor is coupled through the Gi protein and has the effect of diminishing AMPc formation. Prostaglandins that are synthesized in the presence of the COX-2 enzyme located at the level of the nuclear membrane can control nuclear reactions through interactions with receptors activated by peroxisome proliferation (43). This increases the importance of the COX-2 enzyme as a regulating factor in nuclear chemical processes with implications for cell growth and development (45). The activation of leukocytes is achieved by releasing free radicals, proteases and elastases that cause cell injury. The purpose of this inflammatory response is clearly highlighted. Increasing circulating fluid (by vasodilation) and releasing chemotactic factors allow leukocytes and lymphocytes to accumulate in a large number to defend the body (46).

\section{Infection and dissemination in septic shock}

In the last 25 years, several studies in the field have shown that Gram-negative bacteria are the main cause of sepsis production (47). The most frequently isolated species include Staphylococcus aureus (S. aureus), Streptococcus pyogenes (S. pyogenes), Klebsiella spp., Escherichia coli (E. coli) and Pseudomonas aeruginosa (P. Aeuruginosa) (48). Each stage of the infectious process involves the development of different factors of virulence, which is based on the stage of infection.

Some of the most important factors of virulence are represented by toxins. These include endotoxin or lipopolysaccharide, which are found in the external membrane layer of Gram-negative bacteria and others are secreted as exotoxins by other bacteria (49-51).

Bacterial toxins are divided into 3 large classes, depending on the mechanisms: i) Type I toxins that destroy the host cell without penetrating it, such as super-antigens produced by $S$. aureus and $S$. pyogenes; ii) type II toxins such as hemolysins and phospholipases that destroy the membrane of the host cell, penetrate it to interfere and inhibit the cellular defense processes of the host cell; iii) type III toxins known as toxins A/B (because of their binary structure) destroy cellular defense processes to allow their dissemination to different organs. Component B of these toxins binds to the surface of the host cell, while component A has enzyme activity of cellular destruction (52).

The endotoxin, a lipopolysaccharide constituent of the bacterial wall, is the trigger factor which determines the inflammatory response. It has 3 components: An oligosaccharide, responsible for the antigen reaction, a co-lipopolysaccharide, responsible for binding and a lipid, responsible for the toxic action. The activation of monocytes, macrophages and neutrophils, succeeded by the release of proinflammatory mediators and the activation of coagulation, plays an important role in the pathogenesis of septic shock. The inflammatory response, which is also a defense against microorganisms, gets out of control, and produces serious hemodynamic disorders. Endotoxin determines the disturbance of the demand-supply balance of oxygen at the cellular level (increases the need with a decreased supply and oxygen extraction capacity by the cells) which leads to disorders in aerobic cell metabolism and eventually leads to cell death (53).

In the mechanism of septic shock, two pathological phenomena develop: the profound decompensation of circulation and metabolic disturbances that evolve towards an irreversible state. These pathological phenomena determine the two phases of shock: the compensated, early shock (hyperdynamic, reversible) and the decompensated, belated shock (hypodynamic, irreversible). Liberated mediators produce, during the hyperdynamic stage, an increase in heart rate and a decrease in peripheral vascular resistance, which ensures increased tissue needs, the result being vasodilation and hypotension. At the same time, it increases pulmonary vascular resistance, with the development of heart failure. Subsequently, the myocardia is depressed by the myocardial depression factor (myocardial depressant substance, MDS), a proinflammatory cytokine. The consequence of these processes is the decrease in cardiac flow and peripheral vasoconstriction, the evolution being towards the hyperdynamic state (decompensated), with the onset of multiorgan deficiency and therefore cellular death (54). Thus, the polymorphic aspect of this multiple organic insufficiency is complete, along with respiratory failure, hypotension, heart failure, disseminated intravascular coagulation, hemorrhage, hepatic and renal failure, lactic acidosis and coma. The intimate mechanism of shock involves the activation of monocytes, macrophages and neutrophils by the lipopolysaccharide of Gram-negative bacteria. This endotoxin represents a bacterial 'signal molecule', which is specifically linked to an LBP acute phase glycoprotein (LPS binding protein), which will transfer it to the level of CD14 and TLR4 receptors (Toll-like receptors) located on the membrane of monocytes, neutrophils and macrophages, the result being the release of the cascade of inflammation mediators, respectively, cytokines (55-58). The soluble CD14 binds this lipopolysaccharide too and transports it to the level of the vascular endothelial cell, which does not have at the membrane level this type of receptor (55).

\section{Conclusions}

Our analysis of the molecular mechanisms of septic shock has revealed that a better comprehension of sepsis pathophysiology, especially molecular mechanisms of septic shock, will open new therapeutic perspectives. 


\section{Acknowledgements}

This paper is part of a larger, on-going doctoral study of G. P. Gorecki, a Ph.D. Student at 'Titu Maiorescu' University of Bucharest, Romania, Medicine Doctoral School, with Dr Cochior Daniel, University Professor as thesis coordinator. The authors acknowledge the invaluable work in English language editing of the final manuscript performed by Ms. Incze (Kutasi) Réka, Lecturer at 'George Emil Palade' University of Medicine, Pharmacy, Science and Technology of Târgu Mures, Romania.

\section{Funding}

The authors received no funding from any private or state-owned agencies for the development of this study.

\section{Availability of data and materials}

All information provided in this review is documented by relevant references.

\section{Authors' contributions}

GG, DC, CM and ER analyzed the data in the literature and prepared and wrote the manuscript. All authors read and approved the final manuscript for publication.

\section{Ethics approval and consent to participate}

Not applicable.

\section{Patient consent for publication}

Not applicable.

\section{Competing interests}

The authors declare no competing interests in drafting this manuscript.

\section{References}

1. Chang JC: Sepsis and septic shock: Endothelial molecular pathogenesis associated with vascular microthrombotic disease. Thromb J 17: 10, 2019.

2. Al Jalbout N, Troncoso R Jr, Evans JD, Rothman RE and Hinson JS: Biomarkers and molecular diagnostics for early detection and targeted management of sepsis and septic shock in the emergency department. J Appl Lab Med 3: 724-729, 2019.

3. Hynes-Gay P, Lalla P, Leo M, Merrill-Bell A, Nicholson M and Villaruel E: Understanding sepsis: From SIRS to septic shock Dynamics 13: 17-20, 2002.

4. Weil MH and Shubin H: Proposed reclassification of shock states with special reference to distributive defects. Adv Exp Med Biol 23: 13-23, 1971.

5. Simon TP, Thiele C, Schuerholz T, Fries M, Stadermann F, Haase G, Amann KU and Marx G: Molecular weight and molar substitution are more important in HES-induced renal impairment than concentration after hemorrhagic and septic shock. Minerva Anestesiol 81: 608-618, 2015.

6. Peng Y, Zhang W, Xu Y, Li L, Yu W, Zeng J, Ming S, Fang Z, Wang $Z$ and Gao X: Performance of SOFA, qSOFA and SIRS to predict septic shock after percutaneous nephrolithotomy. World J Urol 39: 501-510, 2021.
7. Lee WL: Reply to mehmood: Adrenomedullin: A double-edged sword in septic shock and heart failure therapeutics? Am J Respir Crit Care Med 201: 1165, 2020.

8. Izumida $\mathrm{T}$ and Imamura T: The impact of management using fluid response evaluation on renal and respiratory failure in septic shock. Chest 158: 2706-2707, 2020.

9. GarridoP,RoviraC,CuetoP,Fort-GallifaI,Hernandez-Aguilera A, Cabré N, Luciano-Mateo F, Garcia-Heredia A, Camps J, Joven J, et al: Effect of continuous renal-replacement therapy on paraoxonase-1-related variables in patients with acute renal failure caused by septic shock. Clin Biochem 61: 1-6, 2018.

10. Grattard F, Allegra S, Morel J, Court-Fortune I, Auboyer C, Pozzetto B and Berthelot P: Septic shock due to legionella pneumophila serogroup 2: Usefulness of molecular biology for diagnosis, treatment and epidemiological investigation. Intensive Care Med 36: 1439-1440, 2010.

11. Kalra OP and Raizada A: Approach to a patient with urosepsis. J Glob Infect Dis 1: 57-63, 2009.

12. Kim WY and Hong SB: Sepsis and acute respiratory distress syndrome: Recent update. Tuberc Respir Dis (Seoul) 79: 53-57, 2016.

13. Ramachandran G: Gram-positive and gram-negative bacterial toxins in sepsis: A brief review. Virulence 5: 213-218, 2014.

14. Pranskunas A, Koopmans M, Koetsier PM, Pilvinis V and Boerma EC: Microcirculatory blood flow as a tool to select ICU patients eligible for fluid therapy. Intensive Care Med 39: 612-619, 2013.

15. Edul VK, Ferrara G and Dubin A: Microcirculatory dysfunction in sepsis. Endocr Metab Immune Disord Drug Targets 10: 235-246, 2010.

16. Rodríguez A, Martín-Loeches I and Yébenes JC: New definition of sepsis and septic shock: What does it give us? Med Intensiva 41: 38-40, 2017 (In English, Spanish).

17. Pettila V, Jakob SM and Takala J: The new sepsis/septic shock-3 definition is just not enough-more detailed research is needed. Acta Anaesthesiol Scand 60: 1344-1346, 2016.

18. García-Gigorro R, Molina-Collado Z, Sáez-de la Fuente I, Sanchez-Izquierdo JA and González JC: Application of the new sepsis-3 definition in a cohort of patients with severe sepsis and septic shock admitted to intensive care unit from the emergency department. Med Clin (Barc) 152: 13-16, 2019 (In English, Spanish).

19. Vucelić V, Klobučar I, Đuras-Cuculić B, Grginić A, Prohaska-Potočnik C, Jajić I, Vučičević Z and Degoricija V: Sepsis and septic shock-an observational study of the incidence, management, and mortality predictors in a medical intensive care unit. Croat Med J 61: 429-439, 2020.

20. Daviaud F, Grimaldi D, Dechartres A, Charpentier J, Geri G, Marin N, Chiche JD, Cariou A, Mira JP and Pène F: Timing and causes of death in septic shock. Ann Intensive Care 5: 16, 2015.

21. Angus DC, Linde-Zwirble WT, Lidicker J, Clermont G, Carcillo J and Pinsky MR: Epidemiology of severe sepsis in the United States: Analysis of incidence, outcome, and associated costs of care. Crit Care Med 29: 1303-1310, 2001.

22. Mollura M, Romano S, Mantoan G, Lehman LW and Barbieri R: Prediction of septic shock onset in ICU by instantaneous monitoring of vital signs. Annu Int Conf IEEE Eng Med Biol Soc 2020: 2768-2771, 2020.

23. Abe T, Yamakawa K, Ogura H, Kushimoto S, Saitoh D, Fujishima S, Otomo Y, Kotani J, Umemura Y, Sakamoto Y, et al: Epidemiology of sepsis and septic shock in intensive care units between sepsis-2 and sepsis-3 populations: Sepsis prognostication in intensive care unit and emergency room (SPICE-ICU). J Intensive Care 8: 44, 2020.

24. Jouffroy R, Bloch-Laine E, Maignan M,Le Borgne P, Marjanovic N, Lafon T, Dehdar S, Thomas L, Michelet P and Vivien B: Contribution of capillary refilling time and skin mottling score to predict ICU admission of patients with septic or haemorrhagic shock admitted to the emergency department: A TRCMARBSAU study. Turk J Anaesthesiol Reanim 47: 492-495, 2019.

25. Nathan N, Sculier JP, Ameye L, Paesmans M, Bogdan-Dragos G and Meert AP: Sepsis and septic shock definitions in patients with cancer admitted in ICU. J Intensive Care Med 36: 255-261, 2021.

26. Nemes RM, Pop CS, Calagiu D, Dobrin D, Chetroiu D, Jantea P and Postolache P: Anemia in inflammatory bowel disease more than an extraintestinal complication. Rev Med Chir Soc Med Nat Iasi 120: 34-39, 2016.

27. Pavez N, Kattan E, Vera M, Ferri G, Valenzuela ED, Alegría L, Bravo S, Pairumani R, Santis C, Oviedo V, et al: Hypoxia-related parameters during septic shock resuscitation: Pathophysiological determinants and potential clinical implications. Ann Transl Med 8: 784, 2020 
28. Postolache P, Nemes RM, Petrescu O and Merisanu IO: Smoking cessation, pulmonary rehabilitation and quality of life at smokers with COPD. Rev Med Chir Soc Med Nat Iasi 119: 77-80, 2015.

29. Postolache P, Duceac LD, Vasincu EG and Nemes RM: Chaos and self-structuring behaviors in lung airways. UPB Sci Bull Series A 78: 291-298, 2016.

30. Raşcu A, Naghi E, OŢelea MR, NiŢu FM and Arghir OC: Distinction between mesothelioma and lung adenocarcinoma based on immunohisthochemistry in a patient with asbestos bodies in a bronchoalveolar fluid-case report. Rom J Morphol Embryol 57: 1171-1174, 2016.

31. Wang H, Guo S, Wan C, Yang T, Zeng N, Wu Y, Chen L, Shen Y and Wen F: Tumor necrosis factor- $\alpha-308$ G/A polymorphism and risk of sepsis, septic shock, and mortality: An updated meta-analysis. Oncotarget 8: 94910-94919, 2017.

32. Kothari N, Bogra J, Abbas H, Kohli M, Malik A, Kothari D, Srivastava S and Singh PK: Tumor necrosis factor gene polymorphism results in high TNF level in sepsis and septic shock. Cytokine 61: 676-681, 2013.

33. Phumeetham S, Chat-Uthai N, Manavathongchai $M$ and Viprakasit V: Genetic association study of tumor necrosis factor-alpha with sepsis and septic shock in thai pediatric patients. J Pediatr (Rio J) 88: 417-422, 2012. (In English, Portuguese)

34. Dulhunty JM, Lipman J and Finfer S; Sepsis Study Investigators for the ANZICS Clinical Trials Group: Does severe non-infectious SIRS differ from severe sepsis? Results from a multi-centre Australian and New Zealand intensive care unit study. Intensive Care Med 34: 1654-1661, 2008.

35. Jaramillo-Bustamante JC, Piñeres-Olave BE and GonzálezDambrauskas S: SIRS or not SIRS: Is that the infection? A critical review of the sepsis definition criteria. Bol Med Hosp Infant Mex 77: 293-302, 2020.

36. Shankar-Hari M, Phillips GS, Levy ML, Seymour CW, Liu VX, Deutschman CS, Angus DC, Rubenfeld GD and Singer M; Sepsis Definitions Task Force: Developing a new definition and assessing new clinical criteria for septic shock: For the third international consensus definitions for sepsis and septic shock (Sepsis-3). Jama 315: 775-787, 2016.

37. Song J, Cho H, Park DW, Ahn S, Kim JY, Seok H, Park J and Moon S: The effect of the intelligent sepsis management system on outcomes among patients with sepsis and septic shock diagnosed according to the sepsis-3 definition in the emergency department. J Clin Med 8: 1800, 2019.

38. Sterling SA, Puskarich MA, Glass AF, Guirgis F and Jones AE: The impact of the sepsis-3 septic shock definition on previously defined septic shock patients. Crit Care Med 45: 1436-1442, 2017.

39. Ronco C: Lipopolysaccharide (LPS) from the cellular wall of gram-negative bacteria, also known as endotoxin, is a key molecule in the pathogenesis of sepsis and septic shock. Preface. Blood Purif 37 (Suppl 1): S1, 2014.

40. Ishibe Y, Shibata S, Takahashi G, Suzuki Y, Inoue Y and Endo S Association of type II secretory phospholipase A2 and surfactant protein $\mathrm{D}$ with the pulmonary oxygenation potential in patients with septic shock during polymyxin-B immobilized fiber-direct hemoperfusion. J Clin Apher 32: 302-310, 2017.

41. Charchaflieh J, Wei J, Labaze G, Hou YJ, Babarsh B, Stutz H, Lee H, Worah S and Zhang M: The role of complement system in septic shock. Clin Dev Immunol 2012: 407324, 2012.

42. Oettinger W, Berger D and Beger HG: The clinical significance of prostaglandins and thromboxane as mediators of septic shock. Klin Wochenschr 65: 61-68, 1987.

43. Ball HA, Cook JA, Wise WC and Halushka PV: Role of thromboxane, prostaglandins and leukotrienes in endotoxic and septic shock. Intensive Care Med 12: 116-126, 1986.

44. Tunctan B, Yaghini FA, Estes A and Malik KU: Prostaglandins inhibit cytochrome P450 4A activity and contribute to endotoxin-induced hypotension in rats via nitric oxide production. Arch Pharm Res 31: 856-865, 2008.
45. Tunctan B, Korkmaz B, Sari AN, Kacan M, Unsal D, Serin MS, Buharalioglu CK, Sahan-Firat S, Cuez T, Schunck WH, et al: Contribution of iNOS/sGC/PKG pathway, COX-2, CYP4A1, and gp91(phox) to the protective effect of 5,14-HEDGE, a 20-HETE mimetic, against vasodilation, hypotension, tachycardia, and inflammation in a rat model of septic shock. Nitric Oxide 33: 18-41, 2013.

46. Salvesen O, Reiten MR, Heegaard PM, Tranulis MA, Espenes A, Skovgaard K and Ersdal C: Activation of innate immune genes in caprine blood leukocytes after systemic endotoxin challenge. BMC Vet Res 12: 241, 2016

47. Adamik B, Zielinski S, Smiechowicz J and Kübler A: Endotoxin elimination in patients with septic shock: An observation study. Arch Immunol Ther Exp (Warsz) 63: 475-483, 2015.

48. Curuţiu C, Chifiriuc CM and Mitache MM: Pseudomonas aeruginosa-eukaryotic cell crosstalk: Mediators, mechanisms and implications for the antimicrobial therapy. Curr Org Chem 17: 149-154, 2013.

49. Mitache M, Gheorghe I, Totea G, Bleotu C, Curutiu C, Cochior D, Rusu E and Chifiriuc MC: Biochemical, virulence and resistance features in bacterial strains recovered from hospital surfaces after decontamination with quaternary ammonium compounds, triclosan and iodine disinfectants. Rev Chim (Bucharest) 68: 997-1001, 2017.

50. Elena R, Simona ES, Diana P, Ionela S, Cojocaru M and Tatiana V: Identification of species of the genus Candida by analysis of $5.8 \mathrm{~S}$ rRNA gene. Rom Biotech Lett 20: 10585-10591, 2015.

51. Sârbu I, Vassu T, Chifiriuc MC, Bucur M, Stoica I, Petrut S, Rusu E, Moldovan H and Pelinescu D: Assessment the activity of some enzymes and antibiotic substances sensitivity on pathogenic bacteria species. Rev Chim (Bucharest) 68: 3015-3021, 2017.

52. van der Poll T and Opal SM: Host-pathogen interactions in sepsis. Lancet Infect Dis 8: 32-43, 2008.

53. Busani S, Serafini G, Mantovani E, Venturelli C, Giannella M, Viale P, Mussini C, Cossarizza A and Girardis M: Mortality in patients with septic shock by multidrug resistant bacteria: Risk factors and impact of sepsis treatments. J Intensive Care Med 34: 48-54, 2019

54. He XF, Wu GS, Luo PF, Sun Y, Shi SJ and Xia ZF: Research advances on the molecular mechanisms of vascular permeability in sepsis. Zhonghua Shao Shang Za Zhi 36: 982-986, 2020 (In Chinese).

55. Jiménez-Sousa MA,Liu P,Medrano LM,Fernández-Rodríguez A, Almansa R, Gómez-Sánchez E, Rico L, Lorenzo M, Fadrique A, Tamayo E and Resino S: Association of CD14 rs2569190 polymorphism with mortality in shock septic patients who underwent major cardiac or abdominal surgery: A retrospective study. Sci Rep 8: 2698, 2018.

56. Masson S, Caironi P, Fanizza C, Thomae R, Bernasconi R, Noto A, Oggioni R, Pasetti GS, Romero M, Tognoni G, et al: Circulating presepsin (soluble CD14 subtype) as a marker of host response in patients with severe sepsis or septic shock: Data from the multicenter, randomized ALBIOS trial. Intensive Care Med 41: 12-20, 2015.

57. Luo MC, Zhou SY, Feng DY, Xiao J, Li WY, Xu CD, Wang HY and Zhou T: Runt-related transcription factor 1 (RUNX1) binds to $\mathrm{p} 50$ in macrophages and enhances TLR4-triggered inflammation and septic shock. J BiolChem 291: 22011-22020, 2016.

58. Chattopadhyay S, Veleeparambil M, Poddar D, Abdulkhalek S, Bandyopadhyay SK, Fensterl V and Sen GC: EGFR kinase activity is required for TLR4 signaling and the septic shock response. EMBO Rep 16: 1535-1547, 2015.

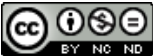

This work is licensed under a Creative Commons Attribution-NonCommercial-NoDerivatives 4.0 International (CC BY-NC-ND 4.0) License. 